\title{
Effects of Temperature and Light on Germination of Urediniospores of the Pearl Millet Rust Pathogen, Puccinia substriata var. indica
}

\author{
H. Tapsoba, Department of Plant Pathology, and J. P. Wilson, USDA-ARS Forage and Turf Research Unit, Uni- \\ versity of Georgia Coastal Plain Experiment Station, Tifton 31793-0748
}

\begin{abstract}
Tapsoba, H., and Wilson, J. P. 1997. Effects of temperature and light on germination of urediniospores of the pearl millet rust pathogen, Puccinia substriata var. indica. Plant Dis. 81:10491052 .

Germination of urediniospores of Puccinia substriata var. indica was evaluated after 2, 4, 6, and $8 \mathrm{~h}$ of incubation in petri dishes containing $2 \%$ water agar under $10,16,20,25,30$, and $35^{\circ} \mathrm{C}$ in light (1650 lux, cool white fluorescent), dark, alternate light-dark, and alternate dark-light. Less than $1 \%$ germination occurred at $35^{\circ} \mathrm{C}$. At $30^{\circ} \mathrm{C}$, percent germination did not significantly change after $4 \mathrm{~h}$. At $10^{\circ} \mathrm{C}$, percent germination increased with longer incubation. Under all illumination conditions, percent maximum germination after 4 to $8 \mathrm{~h}$ occurred at $20-25^{\circ} \mathrm{C}$. Response surface analysis indicated that under all four illumination regimes, urediniospore germination greater than $90 \%$ occurs between 19 and $22^{\circ} \mathrm{C}$ after $6-7 \mathrm{~h}$ of incubation. Two hours of continuous light appeared to significantly delay germination, but exposure to light during the first hour of incubation was stimulatory when followed by $1 \mathrm{~h}$ dark.
\end{abstract}

Pearl millet rust, caused by Puccinia substriata Ell. \& Barth. var. indica Ramachar \& Cummins, has become an important limiting factor for pearl millet (Pennisetum glaucum [L.] R. Br.) grain and forage production in the southeastern United States $(5,11,12)$. Knowledge of the physiologic requirements of the pathogen is a key step to understanding epidemiology of a plant disease. Determining effects of environmental factors such as temperature, moisture, and light on spore germination is important for the creation of favorable conditions for inoculation of plants in the greenhouse, as well as for the choice of more favorable periods for artificial inoculation in the field. Although the effect of temperature on germination of urediniospores of $P$. substriata var. indica was studied previously (4), no information on the interactions of time, light, and temperature on germination is available. Temperature and light have been found to be particularly important in spore germination and subsequent infection of the host plant by many other rust pathogens $(1,3,4,7,8)$. The present study was undertaken to pro-

\section{Corresponding author: H. Tapsoba}

Cooperative investigation of the USDA-ARS and the University of Georgia, College of Agricultural and Environmental Sciences, Agricultural Experiment Station.

Accepted for publication: 7 May 1997.

Publication no. D-1997-0714-01R

This article is in the public domain and not copyrightable. It may be freely reprinted with customary crediting of the source. The American Phytopathological Society, 1997. vide information on the effects and interactions of temperature and light on germination of urediniospores of $P$. substriata var. indica.

\section{MATERIALS AND METHODS}

The experimental design used was a split-split plot design with four replications. For each replication, fresh urediniospores of a bulk collection of $P$. substriata var. indica were collected from 5-week-old Tift 23DB pearl millet plants growing in the greenhouse and were suspended in deionized water containing about 0.05 $\mathrm{ml} / \mathrm{ml}$ of Triton B (approx. 30,000 urediniospores $/ \mathrm{ml}$ ). The urediniospores were collected from 7-day-old pustules using a vacuum spore collector. Germination tests were carried out in petri dishes $(6 \mathrm{~cm}$ diam.) containing $2 \%$ water agar with nalidixic acid and chlortetracycline (75 ppm). Each petri dish received $0.5 \mathrm{ml}$ of the spore suspension uniformly distributed on the medium with a glass rod. The temperature levels were obtained on a heated bench that provided a gradient allowing incubation at the different temperatures simultaneously. Positions of specific temperatures on the bench were identified with a temperature probe. The urediniospores were incubated under six temperatures (10, $16,20,25,30$, or $35^{\circ} \mathrm{C}$ ) for $2,4,6$, or $8 \mathrm{~h}$, under one of four illumination regimes: continuous light, continuous dark, alternate light-dark, and alternate dark-light. Four petri dishes were used for each temperature. In continuous illumination conditions, light or darkness was maintained during the entire incubation time. In alternate illumination conditions, light or darkness was maintained for half of the incubation period. In all experiments, light was provided by two General Electric F40D/Daylight 40W cool white fluorescent lamps suspended $30 \mathrm{~cm}$ above the petri dishes. The average light intensity was $1650( \pm 29)$ lux at the petri dish level. Darkness was achieved by covering the petri dishes with opaque black-colored paper boxes. For each temperature, petri dishes were placed so that the center of the dish was located above the specified temperature on the bench. To ensure that the medium was at the temperature tested, petri dishes were placed on the heated bench at least $15 \mathrm{~min}$ before deposition of the urediniospores.

At the end of each incubation time, a drop of lactophenol cotton blue was deposited at the center of each petri dish to prevent further germination. A glass cover slip was then placed over the spot of lactophenol cotton blue. Using a compound microscope $(150 \times)$, germinated and nongerminated urediniospores were counted in each of 10 randomly selected ocular fields $\left(1.91 \mathrm{~mm}^{2}\right)$ in each petri dish. Urediniospores with germ tube length greater than or equal to spore diameter were considered germinated. The percentage of germinated spores was calculated from all counted spores. The data were subjected to analysis of variance using statistical procedures of SAS (Cary, NC) after an arcsine transformation. The sums of squares were parti-

Table 1. Analysis of variance of the main effects and interactions of illumination, temperature, and incubation time on the germination of urediniospores of Puccinia substriata var. indica

\begin{tabular}{lrcc}
\hline Source of variation & df & Mean square & $\boldsymbol{F}$ \\
\hline Illumination & 3 & 2.10 & $97.83 * * * a$ \\
Temperature & 4 & 21.80 & $1016.05 * * *$ \\
Time & 3 & 6.92 & $322.40^{* * *}$ \\
Illumination*Temperature & 12 & 0.50 & $23.44 * * *$ \\
Illumination*Time & 9 & 0.61 & $28.44 * * *$ \\
Temperature*Time & 12 & 0.28 & $12.85^{* * *}$ \\
Illumination*Temperature*Time & 36 & 0.22 & $10.28^{* * *}$ \\
\hline
\end{tabular}

a Indicates significance at $P=0.0001$. 

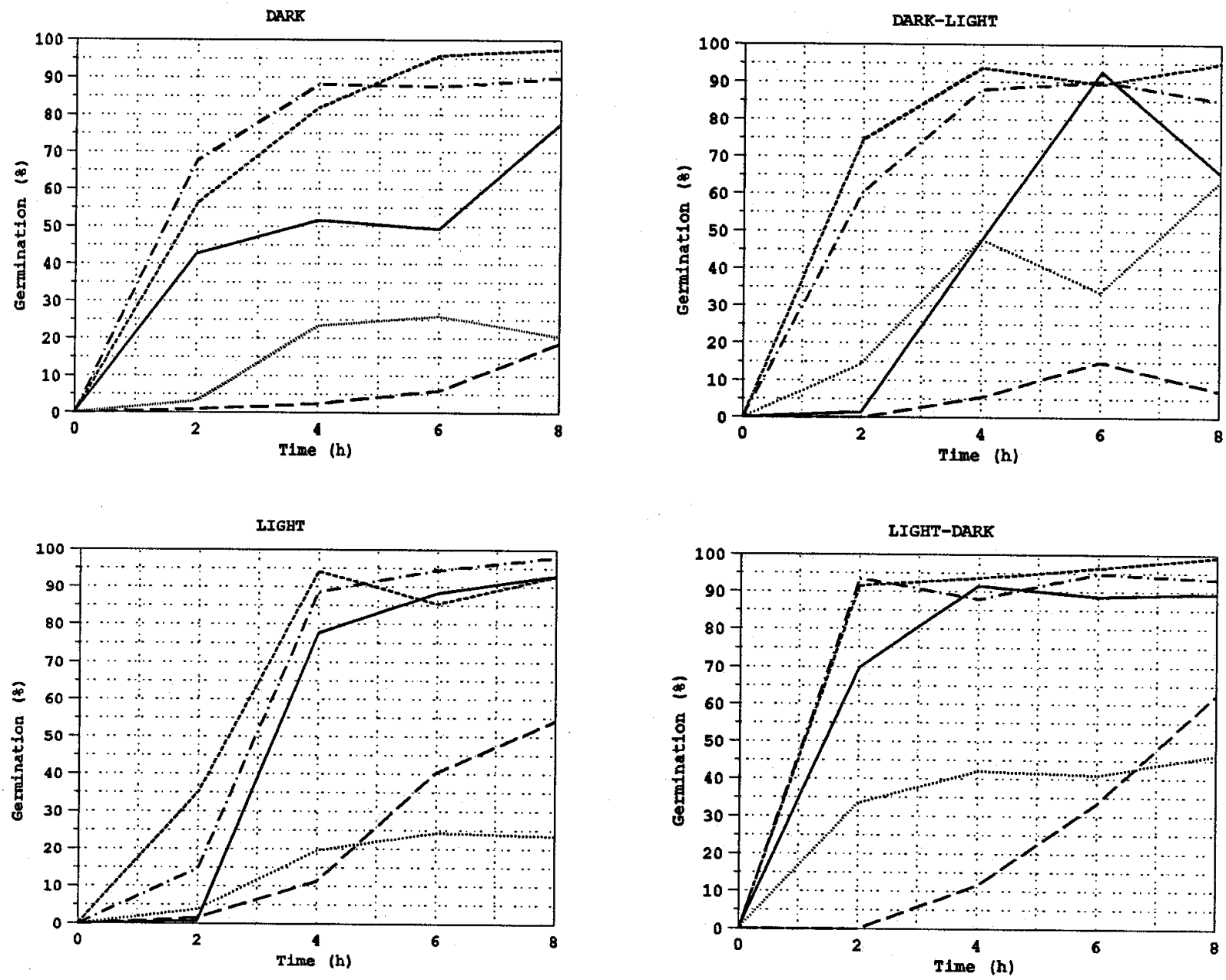

Temperature $\left({ }^{\circ} \mathrm{C}\right)$
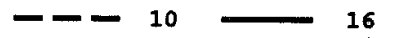

25

30

Fig. 1. Percent germination of urediniospores of Puccinia substriata var. indica in continuous dark, continuous light, alternate dark-light, and alternate light-dark at $10,16,20,25$, and $30^{\circ} \mathrm{C}$ after $2,4,6$, and $8 \mathrm{~h}$ of incubation.

tioned into replication, illumination, temperature, incubation time, and all of the two-way and three-way interactions between illumination, temperature, and incubation time effects. A response surface procedure (SAS, Cary, NC) was also used to fit a second-order regression model of germination rate as a function of temperature and incubation time for each of the illumination regimes.

\section{RESULTS}

The summary of the analysis of variance presented in Table 1 indicates that all main effects and interactions among the three factors (illumination, temperature, and time) were significant $(P<0.0001)$. Figure 1 summarizes the mean results of the four experiments. Results for $35^{\circ} \mathrm{C}$ are not shown because less than $1 \%$ germination occurred under all illumination conditions. At $10^{\circ} \mathrm{C}$, although germination generally increased significantly with longer incubation, it never exceeded $65 \%$. The germination process was very slow at $10^{\circ} \mathrm{C}$, less than $2 \%$ at $2 \mathrm{~h}$ for all illumination conditions. In most cases, percent germination at $30^{\circ} \mathrm{C}$ did not change significantly after $4 \mathrm{~h}$. At 16,20 , and $25^{\circ} \mathrm{C}$, at least half of the urediniospores germinated by $4 \mathrm{~h}$, regardless of illumination. However, the observed maximum percent germination was reached at 20 and $25^{\circ} \mathrm{C}$ with more than $85 \%$ germination by $4 \mathrm{~h}$. The differences between 20 and $25^{\circ} \mathrm{C}$ and the other three temperatures generally remained significant with longer incubation. Over all temperatures, the greatest increase in percent germination was usually observed between the 2- and 4-h incubations.

In continuous dark and alternate darklight conditions, germination at $10^{\circ} \mathrm{C}$ never exceeded $20 \%$. In continuous light and alternate light-dark, however, germination at $10^{\circ} \mathrm{C}$ reached more than $50 \%$ by $8 \mathrm{~h}$. For 2-h incubation, continuous light significantly delayed spore germination compared to the other three illumination regimes. For example, at 20 and $25^{\circ} \mathrm{C}$ under continuous light, less than $35 \%$ of the spores germinated, compared to more than 55\% under the three other illumination regimes. With longer incubation, however, more than $90 \%$ germination occurred. After $2 \mathrm{~h}$ of incubation, germination was significantly higher under alternate lightdark at $16,20,25$, and $30^{\circ} \mathrm{C}$ than under any other illumination regime. At 20 and $25^{\circ} \mathrm{C}$, for example, more than $90 \%$ germination was reached. Alternating light and dark favored germination at $30^{\circ} \mathrm{C}$, which reached more than $30 \%$ compared to less than $4 \%$ under continuous illumination.

The results obtained with the response surface regression analysis to test for the significance of temperature and time effects for each illumination regime are presented in Table 2 . The regression coefficient $\left(r^{2}\right)$ was greater than $80 \%$ in all four cases with the quadratic component of the model explaining at least $50 \%$ of the correlation in all cases. For all four illumination regimes, the effect of temperature on germination was highly significant. From the analysis of variance and the test for 
Table 2. Response surface regression analysis of the effects of temperature and incubation time on the in vitro germination of urediniospores of $P$ uccinia substriata var. indica under four illumination regimes

\begin{tabular}{|c|c|c|c|c|}
\hline \multirow[b]{2}{*}{ Variable } & \multicolumn{4}{|c|}{ Illumination } \\
\hline & Dark & Dark-Light & Light & Light-Dark \\
\hline \multicolumn{5}{|l|}{ Regression coefficient } \\
\hline Linear & $0.147 * * \mathrm{a}$ & $0.272 * *$ & $0.326 * * *$ & $0.094^{* *} *$ \\
\hline Quadratic & $0.697 * * *$ & $0.534 * * *$ & $0.506 * * *$ & $0.801 * * *$ \\
\hline Cross product & 0.000 & 0.001 & 0.018 & 0.018 \\
\hline Total & $0.844 * * *$ & $0.807 * * *$ & $0.850 * * *$ & $0.913 * * *$ \\
\hline \multicolumn{5}{|l|}{ Parameters } \\
\hline Intercept & $-2.996 * * *$ & $-3.811 * * *$ & $-3.659 * * *$ & $-3.202 * * *$ \\
\hline Temperature & $0.348 * * *$ & $0.031 * * *$ & 0.323 *** & $0.392 * * *$ \\
\hline Time & 0.093 & 0.282 & $0.506^{* *}$ & 0.123 \\
\hline Temperature*Temperature & $-0.009 * * *$ & $-0.007 * * *$ & $-0.008 * * *$ & $-0.009 * * *$ \\
\hline Temperature*Time & 0.000 & 0.001 & 0.000 & -0.004 \\
\hline Time*Time & -0.006 & -0.023 & -0.030 & 0.000 \\
\hline \multicolumn{5}{|l|}{ Predicted optimum } \\
\hline Temperature, ${ }^{\circ} \mathrm{C}$ & 20.880 & 21.804 & 19.560 & 20.260 \\
\hline Time, h & 6.781 & 6.399 & 6.800 & 6.800 \\
\hline Predicted germination, $\%$ & $89.72 \pm 12.25^{b}$ & $91.78 \pm 19.61$ & $95.71 \pm 19.11$ & $97.77 \pm 12.82$ \\
\hline
\end{tabular}

a $* *$ and $* * *$ indicate significance at $P=0.001$ and $P=0.0001$, respectively.

b $95 \%$ confidence interval.

significance for the parameter estimates (Table 2), it appeared that the test for time was not significant, except in light. However, the ridge analysis indicated that, under all four illumination regimes, maximum germination rates will result from long incubation periods ( $\geq 6 \mathrm{~h}$ ). The ridge analysis also showed that the optimum temperature for germination lies between 19 and $22^{\circ} \mathrm{C}$ with a predicted germination rate close to $90 \%$ or more after $6.5-7 \mathrm{~h}$ of incubation.

\section{DISCUSSION}

Germination of urediniospores of $P$. substriata var. indica is significantly affected by the environmental factors acting on the spores during the germination process. The predicted optimum temperatures from these experiments $\left(19-22^{\circ} \mathrm{C}\right)$ are similar to previously reported results (4). Regardless of the illumination regime, percent germination surpassed $85 \%$ after 6 $\mathrm{h}$ at the optimum temperatures. The ridge system analysis of the response surface regression indicated that germination frequencies greater than $90 \%$ can be obtained at temperatures between 19 and $22^{\circ} \mathrm{C}$ for incubation periods of 6-7 h. The fact that the test for the time factor was not significant in the response surface regression indicated that if further experimentation was to be undertaken, it might be best to work with long incubation periods $(6-8 \mathrm{~h})$ while concentrating on the effect of temperature. Misra and Prasada (4) examined germination after $24 \mathrm{~h}$ without defining illumination conditions; however, crop canopies frequently will not retain moisture for $24 \mathrm{~h}$. Under natural conditions, illumination will always be a variable that may affect spore germination, therefore, the study of the interaction of time and illumination with temperature was informative.

With illumination, the first $2 \mathrm{~h}$ of incubation appeared to be the most important.
Although continuous light for $2 \mathrm{~h}$ incubation delayed germination, exposure to light during the first hour of incubation was stimulatory when followed by $1 \mathrm{~h}$ of dark. Similar observations were made in the case of $P$. striiformis for which it was reported that prior exposure to light (approx. 6400 lux) enhances germination of urediniospores (9). Givan and Bromfield (1) also observed that urediniospores of $P$. graminis var. tritici incubated under $1 \mathrm{~h}$ of light (approx. 4300 lux) followed by $1 \mathrm{~h}$ of darkness show considerably better germination than those incubated in continuous light for $2 \mathrm{~h}$.

The effect of continuous light observed here is far less drastic than reported from studies of other rust pathogens $(1,8)$. The low intensity of the light used, 1650 lux compared to more than 5000 lux in most studies, was limited only by the available experimental equipment and might have contributed to the differences. The existence of a threshold of photo-inhibition has been demonstrated for other rust pathogens such as $P$. graminis f. sp. tritici (2) and $P$. arachidis (8).

These experiments provide useful information on the effects of light and temperature on the germination of urediniospores of $P$. substriata var. indica. The optimum temperatures determined in this study fall within the average daily minimum and maximum temperatures (70-year averages) recorded in south Georgia during the summer months of July, August, and September when local epidemics are first initiated. During those months, conditions are made even more favorable by the prevailing high relative humidity, which is correlated with greater rust severities in the field (6). The temperature range of 10 $25^{\circ} \mathrm{C}$ included in these experiments falls within the average minimum and maximum daily temperatures until 4 November, after which the average minimum temperatures fall below $10^{\circ} \mathrm{C}$. The potential for urediniospore germination at low temperatures with short incubation periods validates our observations that rust epidemics progress until the pearl millet foliage is killed by frost (10). Because of the observed interactions of illumination and low temperature we can speculate that urediniospore germination during the cooler fall months may occur predominantly late in the day or in early evening, as the light intensity approaches the level used in these experiments. Caution should be observed, however, when extrapolating the results of germination on an artificial moist medium to field conditions for which experimental data still remain to be collected. The highly variable levels of light, temperature, and moisture in the field may impose different constraints on germination than the relatively constant conditions provided on an artificial medium.

\section{ACKNOWLEDGMENTS}

We thank Andy Hornbuckle for technical assistance and Roger N. Gates for use of laboratory facilities.

\section{LITERATURE CITED}

1. Givan, C. V., and Bromfield, K. R. 1964. Light inhibition of germination in Puccinia graminis var. tritici. Phytopathology 54:382-384.

2. Knight, I. K., and Lucas, J. A. 1981. Photo control of Puccinia graminis f. sp. tritici urediniospore germination in the field. Trans. Br. Mycol. Soc. 77:519-527.

3. Kramer, C. L., and Eversmeyer, M. G. 1992. Effects of temperature on germination and germ-tube development of Puccinia recondita and $P$. graminis urediniospores. Mycol. Res. 96:689-693.

4. Misra, A., and Prasada R. 1971. Studies on uredospore germination and incubation period of bajra rust caused by Puccinia penniseti. Indian J. Mycol. Plant Pathol. 1:103-107.

5. Monson, W. G., Hanna, W. W., and Gaines, T. P. 1986. Effects of rust on yield and quality of pearl millet forage. Crop Sci. 26:637-639.

6. Muthusamy, S., Padmanaban, D., Nagarajan, R., and Ragupathy, N. 1981. Incidence of pearl millet rust in relation to sowing time and relative humidity. Madras Agric. J. 68:527-529. 
7. Sood, P. N., and Wiese, M. V. 1974. Effects of pregermination environments on the germinability of urediniospores of two wheat rust fungi. Phytopathology 64:1244-1248.

8. Subrahmanyam, P., Reddy, P. M., and McDonald, D. 1988. Photosensitivity of urediniospore germination in Puccinia arachidis. Trans. Br. Mycol. Soc. 90:229-232.
9. Tollenaar, H., and Houston, B. R. 1966. Effect of temperature during uredospore production and light on in vitro germination of urediniospores of Puccinia striiformis. Phytopathology 56:787-790.

10. Wilson, J. P. 1994. Field and greenhouse evaluations of pearl millet for partial resistance to Puccinia substriata var. indica. Plant
Dis. 78:1202-1205.

11. Wilson, J. P., Gates, R. N., and Hanna, W. W. 1991. Effect of rust on yield and digestibility of pearl millet forage. Phytopathology 81:233-236.

12. Wilson, J. P., Hanna, W. W., and Gascho, G. J. 1996. Pearl millet grain yield loss from rus infection. J. Prod. Agric. 9:543-545. 